\title{
Effect of 6 months of GH treatment on myosin heavy chain composition in GH-deficient patients
}

\author{
Jens R Daugaard, Margareta Bramnert ${ }^{1}$, Per Manhem ${ }^{1}$, Tomas Endre ${ }^{2}$, Leif C Groop ${ }^{1}$, Monika Löfman ${ }^{3}$ \\ and Erik A Richter
}

\begin{abstract}
Copenhagen Muscle Research Centre, August Krogh Institute, University of Copenhagen, 13 Universitetsparken, DK-2100 Copenhagen O, Denmark, ${ }^{1}$ Department of Endocrinology, Malmö University Hospital, Lund University, Malmö, Sweden, ${ }^{2}$ Department of Medicine, Malmö University Hospital, Lund University, Malmö, Sweden and ${ }^{3}$ Fourth Department of Medicine, Helsinki University Hospital, Helsinki, Finland
\end{abstract}

(Correspondence should be addressed to J R Daugaard; Email: JRDaugaard@aki.ku.dk)

\begin{abstract}
Objective: To investigate the effect of GH on myosin heavy chain (MHC) isoform composition, physical fitness and body composition in GH-deficient (GHD) patients.

Design: Twenty-two GHD patients were randomized in a double blind manner and half were treated with recombinant human $\mathrm{GH}(\mathrm{rhGH})$ and half were treated with placebo for 6 months. Twelve agematched controls were also included in the study.

Methods: MHC isoform composition in biopsies obtained from the vastus lateralis muscle was determined using SDS-PAGE. Physical fitness was determined on a bicycle ergometer and body composition was determined using bioelectrical impedance analysis.

Results: More MHC IIX $(28.9 \pm 4.1 \%$ and $10.0 \pm 3.1 \%$ in GHD and controls respectively (means \pm s.E.M.)) and less MHC I ( $36.2 \pm 2.4 \%$ and $51.7 \pm 3.9 \%$ in GHD and controls respectively (means \pm s.E.M.)) were present in the GHD patients compared with the controls. No significant difference in the amount of MHC IIA was detected. Linear regression was used to determine the relationship between variables. There were no significant relationships between the concentration of insulin-like growth factor-I (IGF-I) or the body composition and the MHC composition. Maximal oxygen uptake $\left(\mathrm{VO}_{2} \mathrm{max}\right)$ per $\mathrm{kg}$ body weight (BW) (litres/min per kg) correlated significantly with the amount of MHC I $(r=0.60)$ and MHC IIX $(r=-0.72)$ but not with the amount of MHC IIA $(r=0.35)$. Treatment of GHD patients with rhGH for 6 months increased the concentration of IGF-I, lean body mass and decreased fat mass but had no effect on MHC composition and physical fitness.

Conclusions: We conclude that a major part of the differences in MHC composition between GHD patients and age-matched controls can be explained by variation in physical fitness. The severity of the GHD and the body composition does not seem to be important for the MHC composition. Furthermore, treatment with GH for 6 months does not affect MHC composition in GHD patients.
\end{abstract}

European Journal of Endocrinology $141342-349$

\section{Introduction}

The myosin molecule consists of two heavy chains and four light chains expressed in a cell-specific manner and both the myosin light chains and especially the myosin heavy chains (MHCs) have been shown to be important in determining the contractile properties of skeletal muscle (1). In human skeletal muscle the MHCs can be classified as MHC I, MHC IIA and MHC IIB on the basis of differences in their electrophoretic mobility. Since the transcript from the fastest human isoform (MHC IIB) is homologous to the rat MHC IIX isoform (2), and thus may correspond to rat MHC IIX (3), MHC IIX was chosen to designate the fastest human isoform in the present paper.
Growth hormone (GH) is an anabolic, lipolytic and diabetogenic hormone. The anabolic effects of $\mathrm{GH}$ are the most important and include promotion of linear growth in children (4) and maintenance of muscle strength and size in adults (5). In $\mathrm{GH}$-deficient (GHD) patients fat mass may be increased (6) and skeletal muscle mass (6), exercise capacity (7) and skeletal muscle strength (8) decreased compared with age-matched controls. Since the relative proportions of MHC I, MHC IIA and MHC IIX are the major determinants of the maximum velocity of shortening in human skeletal muscle (1), the impaired muscle function in GHD patients could therefore be caused by an altered MHC composition.

In genetically $\mathrm{GH}$-deficient rats $(\mathrm{dw} / \mathrm{dw})$ and in hypophysectomized rats there is a decreased proportion of 
type I fibres and MHC I and an increased proportion of type II fibres and MHC II in skeletal muscle compared with a group of age-matched control rats $(9,10)$. Since treatment with GH in hypophysectomized and dw/dw rats has been shown to change fibre type composition in some (9-11) but not all studies $(12,13)$ and since treatment with GH to GHD patients has been shown to significantly increase skeletal muscle mass, exercise capacity and skeletal muscle strength $(6,7,14,15)$, a relationship between muscle function and muscle fibre composition could exist.

The aim of the present study was to investigate $\mathrm{MHC}$ isoform composition in GHD and the effects of $\mathrm{GH}$ treatment. Furthermore, we investigated the severity of GHD, physical fitness and body composition in GHD and the relation to MHC isoform composition.

\section{Materials and methods}

\section{Subjects}

Fifteen male and seven female GHD patients were included in the study according to the following criteria: (1) age 20-65 years; (2) a maximal GH concentration peak of less than $9 \mathrm{mIU} / \mathrm{l}$ following provocation with either insulin-induced hypoglycaemia, arginine or clonidine; (3) deficient in $\mathrm{GH}$ for more than 12 months; and (4) patients with multiple deficiencies must have been on stable replacement therapy for more than 6 months.
One patient (patient no. 1) was treated with simvastatin, cholestyramine and dikumarol. The individual characteristics of the patients are shown in Table 1. Twelve normal age-matched male controls were selected on the basis of being clinically healthy and receiving no medication. The patients and the controls received both written and verbal information about the study, and their written informed consent was obtained. The study was approved by the Ethics Committee at Lund and Helsinki University. Lean body mass (LBM) was determined using bioelectrical impedance analysis (BIA) (Akern RJL, Florence, Italy). Fat mass was calculated as body weight (BW) minus LBM, and body mass index (BMI) was calculated as BW/height ${ }^{2}$.

\section{GH administration}

The patients were randomized in a double-blind manner and instructed to treat themselves with daily subcutaneous injections of recombinant human GH (rhGH) (Genotropin, Pharmacia \& Upjohn, Stockholm, Sweden) (GHD-GH) or placebo (GHD-PLA). Ten patients received an $\mathrm{rhGH}$ dose of $0.125 \mathrm{IU} / \mathrm{kg}$ per week $(\sim 0.04 \mathrm{mg} / \mathrm{kg}$ per week) for 1 month followed by 5 months' treatment with $0.25 \mathrm{IU} / \mathrm{kg}$ per week $(\sim 0.08 \mathrm{mg} / \mathrm{kg}$ per week). In 12 patients the dose of $\mathrm{GH}$ was $0.20 \mathrm{IU} / \mathrm{kg}$ per week $(\sim 0.07 \mathrm{mg} / \mathrm{kg}$ per week) during the entire treatment period. In GHD-PLA an equivalent volume of placebo was injected.

Table 1 Characteristics of the GHD patients.

\begin{tabular}{|c|c|c|c|c|c|c|}
\hline Patient no. & Sex & $\begin{array}{c}\text { Age } \\
(\mathrm{yr})\end{array}$ & Aetiology & $\begin{array}{c}\text { Pituitary } \\
\text { deficiency }\end{array}$ & $\begin{array}{c}\text { Estimated } \\
\text { duration of } \\
\text { GHD (yr) }\end{array}$ & $\begin{array}{l}\text { GH peak at } \\
\text { stimulation } \\
(\mathrm{mlU} / \mathrm{l})\end{array}$ \\
\hline 1 & M & 54 & A & & 3 & 2.9 \\
\hline 2 & M & 38 & NS & $\mathrm{A}, \mathrm{T}, \mathrm{G}$ & 2 & 0.3 \\
\hline $3^{*}$ & M & 36 & NS & $A, T, G$ & 19 & 0.1 \\
\hline 4 & M & 46 & NS & $A, T, G$ & 12 & $<0.1$ \\
\hline 5 & $\mathrm{~F}$ & 39 & 1 & A & 3 & 0.1 \\
\hline 6 & M & 47 & A & $\mathrm{A}, \mathrm{T}, \mathrm{G}$ & 15 & 0.2 \\
\hline 7 & $\mathrm{~F}$ & 44 & NS & $\mathrm{A}, \mathrm{T}, \mathrm{G}$ & 7 & 0.1 \\
\hline $8^{*}$ & M & 28 & C & $\mathrm{A}, \mathrm{T}, \mathrm{G}, \mathrm{V}$ & 19 & 1.0 \\
\hline 9 & $M$ & 49 & $\mathrm{C}$ & $\mathrm{A}, \mathrm{T}, \mathrm{G}$ & 31 & 0.5 \\
\hline 10 & M & 53 & NS & $A, G$ & 6 & 2.8 \\
\hline 11 & $\mathrm{~F}$ & 44 & PRL & $A, G$ & 9 & 0.1 \\
\hline 12 & M & 63 & NS & & 12 & 1.6 \\
\hline 13 & M & 58 & C & & 5 & 1.6 \\
\hline 14 & M & 47 & NS & G & 2 & 0.5 \\
\hline 15 & $\mathrm{~F}$ & 46 & $\mathrm{H}$ & $\mathrm{A}, \mathrm{T}, \mathrm{G}$ & 1 & 0.2 \\
\hline 16 & $\mathrm{~F}$ & 46 & C & $\mathrm{A}, \mathrm{T}, \mathrm{G}, \mathrm{V}$ & 1 & 0.5 \\
\hline 17 & $\mathrm{M}$ & 56 & NS & $\mathrm{A}, \mathrm{T}, \mathrm{G}, \mathrm{V}$ & 1 & 0.1 \\
\hline 18 & $\mathrm{~F}$ & 30 & C & $\mathrm{A}, \mathrm{T}, \mathrm{G}, \mathrm{V}$ & 10 & 0.3 \\
\hline $19^{*}$ & M & 28 & 1 & G & 23 & 0.1 \\
\hline 20 & $M$ & 54 & NS & $\mathrm{G}$ & 1 & 4.9 \\
\hline 21 & $\mathrm{M}$ & 42 & NS & $\mathrm{A}, \mathrm{T}, \mathrm{G}$ & 1 & 1.1 \\
\hline 22 & $\mathrm{~F}$ & 58 & 1 & $A, T, G$ & 1 & 0.5 \\
\hline
\end{tabular}

* Previously GH-treated.

Etiology: NS, nonsecreting adenoma; $\mathrm{A}$, treated acromegaly; PRL, prolactinoma; $\mathrm{C}$, craniopharyngioma; I, idiopathic; $\mathrm{H}$, hypophysitis.

Pituitary insufficiency in addition to GHD: A, ACTH; T, TSH; G, gonadotrophin; V, ADH. 


\section{Physical fitness evaluation}

Of the $22 \mathrm{GHD}$ patients the physical fitness was evaluated in the last 12 patients before and after treatment with either placebo or rhGH. The physical fitness was evaluated in all the age-matched controls. For half of the GHD patients and for all the controls a submaximal exercise test (which lasted for 6 min with continuous monitoring of heart rate) was performed on a bicycle ergometer using a workload of 100-250 W depending on weight and self-reported physical activity. Mean heart rate during the last 2 min of work (steady state $>120$ beats/min) was used for calculation of maximal heart rate and maximal oxygen uptake $\left(\mathrm{VO}_{2} \mathrm{max}\right)$ according to Åstrand (16). Results obtained by using this method have been shown to correlate well with direct measurements of $\mathrm{VO}_{2} \max (16)$. The other half of the GHD patients performed a maximum exercise test on an electrically braked bicycle ergometer (Bosch EAG 551). Subjects exercised to exhaustion, with the load increased every minute by $10 \mathrm{~W}$ for women and $15 \mathrm{~W}$ for men. Expired gas was sampled continuously via a mixing chamber and analysed for the concentration of $\mathrm{O}_{2}$ and $\mathrm{CO}_{2}$ (Sensor Medics 2900). Measurements were obtained every $20 \mathrm{~s}$ during rest in the sitting position on the bicycle and every $20 \mathrm{~s}$ during exercise. $\mathrm{VO}_{2}$ max was determined as the highest value recorded during the last minute of exercise and according to the levelling-off criterion (17). Finally, although two different methods were used for determining the $\mathrm{VO}_{2} \max$ in the present study, subjects were always tested with the same method following treatment. During exercise testing, heart rate was continuously recorded using an electrocardiograph.

\section{Plasma analysis}

Plasma insulin-like growth factor-I (IGF-I) levels were determined using a commercial RIA kit from Nichols Institute (San Juan Capistrano, CA, USA). The interand intra-assay coefficient of variation was less than $5 \%$.

\section{Muscle biopsies}

Muscle biopsies were taken under lignocaine anaesthesia from the vastus lateralis muscle using a Bergstöm needle (18). The tissue was embedded in Tissue-Tek (Mills Inc., IN, USA) and immediately frozen in isopentane cooled in liquid nitrogen. Muscle samples were stored at $-70{ }^{\circ} \mathrm{C}$ until analysed.

\section{MHC analysis}

MHC analysis was performed on the muscle samples using SDS-PAGE. The protocol for analysing the samples was based on the procedure described by Betto et al. (19). Briefly, in a cryotome five to ten serial crosssections were cut $(20 \mu \mathrm{m}$ thick) and placed in $0.5-$ $1.0 \mathrm{ml}$ lysing buffer consisting of $10 \%(\mathrm{w} / \mathrm{v})$ glycerol,

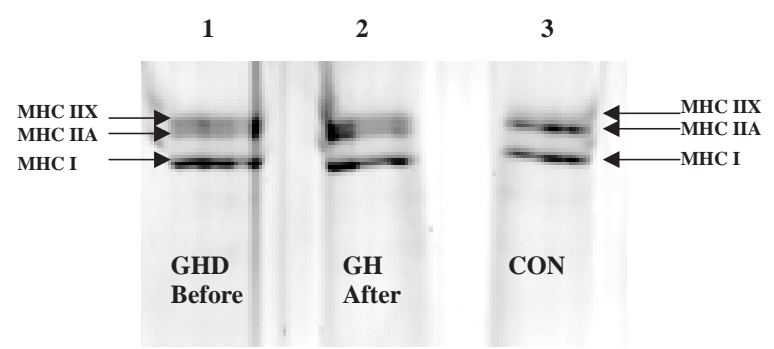

Figure 1 Representative SDS-PAGE of MHC composition in human skeletal muscle. Lane 1 shows the MHC composition in one of the GHD patients before treatment with rhGH and lane 2 shows the MHC composition in the same patient after 6 months of treatment with rhGH. Lane 3 shows the MHC composition in one of the controls. Note the relatively large amount of MHC IIX in the GHD patient compared with the control subject. Also note that the MHC composition in the GHD patient is unchanged after treatment with rhGH for 6 months.

$5 \%(\mathrm{w} / \mathrm{v}) 2$-mercaptoethanol and 2.3\% (w/v) SDS in $62.5 \mathrm{mmol} / \mathrm{l}$ Tris(hydroxymethyl)aminomethane (Tris) buffer $(\mathrm{pH} 6.8)$ and heated for $10 \mathrm{~min}$ at $60{ }^{\circ} \mathrm{C}$. Small amounts $(1-3 \mu \mathrm{l})$ were loaded on SDS-PAGE gels, containing $6 \%$ polyacrylamide and $37.5 \%$ glycerol. Gels were run for $20 \mathrm{~h}$ at $70 \mathrm{~V}$ followed by $4 \mathrm{~h}$ at $200 \mathrm{~V}$, silver stained using a kit (Pharmacia Biotech, Uppsala, Sweden) whereafter the MHC content was quantified. Densitometric scanning was performed using a onedimensional software (CREAM by Kem-En-Tec Software Systems, Copenhagen, Denmark). By using this technique it is possible to distinguish three bands corresponding to MHC I, MHC IIA and MHC IIX based on differences in their electrophoretic mobility (Fig. 1).

\section{Statistics}

Sigma Stat version 2.01 (Jandel Corporation, San Rafael, CA, USA) was used for statistical analysis. Data in the text, tables and figures are given as means \pm s.E.M. Nonparametric tests, Wilcoxon signed rank test (paired data) and Mann-Whitney rank sum test (unpaired data) were used where appropriate. Additionally, linear regression analysis was performed. $P$ values $<0.05$ were considered statistically significant.

\section{Results \\ Characteristics of the patients and the control subjects}

The age was $47 \pm 3,45 \pm 3$ and $37 \pm 2$ years and the height was $175 \pm 5,174 \pm 3$ and $180 \pm 2 \mathrm{~cm}$ in GHDGH, GHD-PLA and in the controls, respectively. No significant differences in age and height were observed between the groups. Before treatment the BW and the BMI were significantly higher in GHD-PLA than in both the GHD-GH group and the controls (Table 2). Before treatment the fat mass was higher in the two groups of 
Table 2 Body composition and plasma IGF-I concentration in GHD patients before and after treatment with either placebo (GHD-PLA) or rhGH (GHD-GH) for 6 months and in normal age-matched control subjects (Control). Values are mean \pm S.E.M. $P$ values were obtained using Wilcoxon signed rank test (before-after) and Mann-Whitney rank sum test (after comparisons).

\begin{tabular}{|c|c|c|c|c|c|}
\hline & \multicolumn{2}{|c|}{ GHD-PLA } & \multicolumn{2}{|c|}{ GHD-GH } & \multirow[b]{2}{*}{$\begin{array}{l}\text { Control } \\
(n=12)\end{array}$} \\
\hline & $\begin{array}{l}\text { Before } \\
(n=11)\end{array}$ & $\begin{array}{c}\text { After } \\
(n=11)\end{array}$ & $\begin{array}{l}\text { Before } \\
(n=11)\end{array}$ & $\begin{array}{c}\text { After } \\
(n=11)\end{array}$ & \\
\hline BW (kg) & $95.7 \pm 4.9^{\star} \dagger$ & $93.8 \pm 4.6$ & $81.7 \pm 5.8$ & $81.9 \pm 6.2$ & $81.2 \pm 2.7$ \\
\hline LBM (kg) & $68.4 \pm 4.4$ & $67.4 \pm 4.3$ & $59.0 \pm 4.7$ & $62.7 \pm 5.3 \neq$ & $65.0 \pm 1.4$ \\
\hline Fat mass $(\mathrm{kg})$ & $27.3 \pm 3.3^{*}$ & $26.4 \pm 3.2$ & $22.7 \pm 2.4^{*}$ & $19.2 \pm 1.9 \neq$ & $16.2 \pm 2.5$ \\
\hline BMI $\left(\mathrm{kg} / \mathrm{m}^{2}\right)$ & $31.7 \pm 1.8^{*} \dagger$ & $31.1 \pm 1.8$ & $26.6 \pm 1.4$ & $26.6 \pm 1.5$ & $25.1 \pm 1.0$ \\
\hline IGF-I $(\mu \mathrm{g} / \mathrm{I})$ & $115 \pm 12^{*}$ & $102 \pm 11^{*}$ & $114 \pm 26^{*}$ & $306 \pm 47 \ddagger$ & $152 \pm 8$ \\
\hline
\end{tabular}

* Significantly $(P<0.05)$ different from Control.

†Significantly $(P<0.05)$ different from GHD-GH Before.

$\ddagger$ Significantly $(P<0.05)$ different from Before.

Table 3 Physical performance in GHD patients before and after treatment with either placebo (GHD-PLA) or rhGH (GHD-GH) for 6 months and in normal age-matched control subjects (Control). Values are mean \pm s.E.M. $P$ values were obtained using Wilcoxon signed rank test (before-after) and Mann-Whitney rank sum test (after comparisons).

\begin{tabular}{|c|c|c|c|c|c|}
\hline & \multicolumn{2}{|c|}{ GHD-PLA } & \multicolumn{2}{|c|}{ GHD-GH } & \multirow[b]{2}{*}{$\begin{array}{l}\text { Control } \\
(n=12)\end{array}$} \\
\hline & $\begin{array}{l}\text { Before } \\
(n=6)\end{array}$ & $\begin{array}{c}\text { After } \\
(n=6)\end{array}$ & $\begin{array}{l}\text { Before } \\
(n=6)\end{array}$ & $\begin{array}{c}\text { After } \\
(n=6)\end{array}$ & \\
\hline Maximal heart rate (beats/min) & $159 \pm 5$ & $159 \pm 6$ & $153 \pm 5$ & $171 \pm 7$ & ND \\
\hline $\mathrm{VO}_{2} \max (\mathrm{I} / \mathrm{min})$ & $2.4 \pm 0.2^{*}$ & $2.9 \pm 0.2$ & $2.4 \pm 0.1^{*}$ & $2.4 \pm 0.2$ & $4.1 \pm 0.3$ \\
\hline $\mathrm{VO}_{2}$ max per kg BW (ml/min per kg) & $25.7 \pm 3.0^{*}$ & $31.5 \pm 2.4$ & $33.5 \pm 3.3^{*}$ & $32.0 \pm 1.6$ & $51.3 \pm 4.5$ \\
\hline $\mathrm{VO}_{2}$ max per $\mathrm{kg}$ LBM (ml/min per kg) & $35.3 \pm 4.4^{*}$ & $42.0 \pm 2.5$ & $46.5 \pm 5.1^{*}$ & $42.3 \pm 2.5$ & $63.1 \pm 4.7$ \\
\hline
\end{tabular}

* Significantly $(P<0.05)$ different from Control.

ND, not determined.

GHD patients compared with the controls and LBM was the same in the three groups (Table 2). Treatment with rhGH for 6 months significantly increased LBM and decreased the fat mass. No significant changes were seen in BW and BMI (Table 2). The plasma IGF-I concentration before treatment was identical in GHDPLA and GHD-GH and for both groups significantly lower than in the controls (Table 2). rhGH treatment significantly increased the plasma IGF-I concentration (Table 2).

\section{Physical performance}

Physical performance measured as $\mathrm{VO}_{2} \max , \mathrm{VO}_{2} \mathrm{max}$ per kg BW and $\mathrm{VO}_{2}$ max per kg LBM were significantly $(P<0.05)$ lower in both groups of GHD patients compared with the controls (Table 3). Physical performance was not affected by treatment with rhGH for 6 months (Table 3). Furthermore, no difference in maximal heart rate could be found between the two groups and treatment with rhGH for 6 months had no significant effect on maximal heart rate in GHD patients (Table 3).

\section{Amount of MHC}

In the entire group of GHD patients, the amount of MHC I was $36.2 \pm 2.4 \%$, the amount of MHC IIA was
$34.8 \pm 3.5 \%$ and the amount of MHC IIX $28.9 \pm 4.1 \%$ $(n=22)$ (Fig. 2). In the controls, the amount of MHC I was $51.7 \pm 3.9 \%$, the amount of MHC IIA was $38.3 \pm 3.3 \%$ and the amount of MHC IIX $10.0 \pm 3.1 \%$ $(n=12)$ (Fig. 2). The amount of MHC I and MHC IIX was found to be significantly $(P<0.05)$ different from the age-matched control group but no difference in MHC IIA could be seen between the groups (Fig. 2). Similar results were found after excluding the women from the study and after excluding the two patients with childhood onset GHD (nos 8 and 19 (Table 1)) (data not shown). Treatment with rhGH for 6 months had no effect on the skeletal muscle MHC isoform composition in GHD (Table 4). Thus, both before and after treatment with rhGH the MHC composition in both GHD groups was significantly $(P<0.05)$ different from the MHC composition in the age-matched control group (Table 4) with an amount of MHC I which was significantly $(P<0.05)$ lower and an amount of MHC IIX which was significantly $(P<0.05)$ higher in the GHD patients (Table 4) compared with the age-matched control group. No difference in the amount of MHC IIA was found between the groups (Table 4).

\section{Linear regression}

For the entire group of GHD patients and controls, significant correlations were found between the amount 


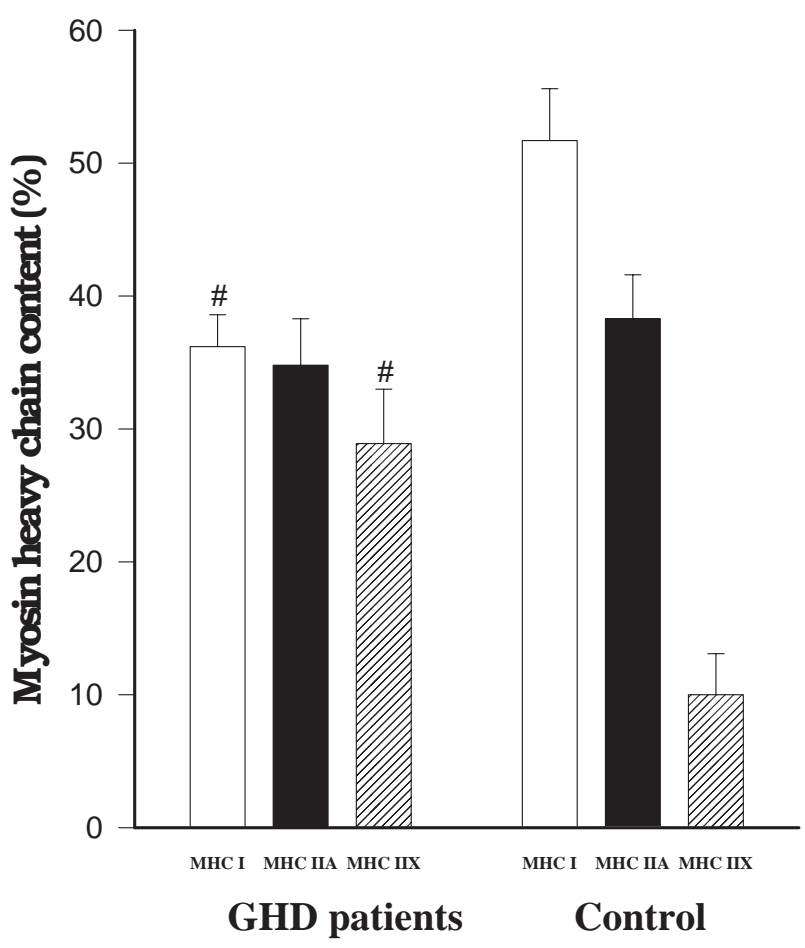

Figure 2 Electrophoretically determined amount of MHC I, MHC IIA and MHC IIX in the entire group of GHD patients $(n=22)$ (beforetreatment values were used) and age-matched control subjects $(n=12)$. \#Significantly $(P<0.05)$ different from control. $P$ values were obtained using the Mann-Whitney rank sum test.

of MHC I (positive), MHC IIX (negative) and the $\mathrm{VO}_{2}$ max per $\mathrm{kg} \mathrm{BW}$ (Fig. 3), the $\mathrm{VO}_{2} \max$ (data not shown), and to the $\mathrm{VO}_{2}$ max per $\mathrm{kg}$ LBM (data not shown). No significant relationship was found to MHC IIA. Within-group statistical analysis revealed that the significant positive correlations between MHC I, the significant negative correlation to MHC IIX and the not significant relationship between MHC IIA on the one hand and the $\mathrm{VO}_{2}$ max per $\mathrm{kg} \mathrm{BW}$ on the other hand were maintained in the group of age-matched controls (data not shown). In the group of GHD patients only the significant negative relationship between MHC IIX and $\mathrm{VO}_{2}$ max per $\mathrm{kg} \mathrm{BW}$ was maintained and no significant relationship between $\mathrm{MHC}$ I, MHC IIA and $\mathrm{VO}_{2}$ max per kg BW could be seen (data not shown).
A

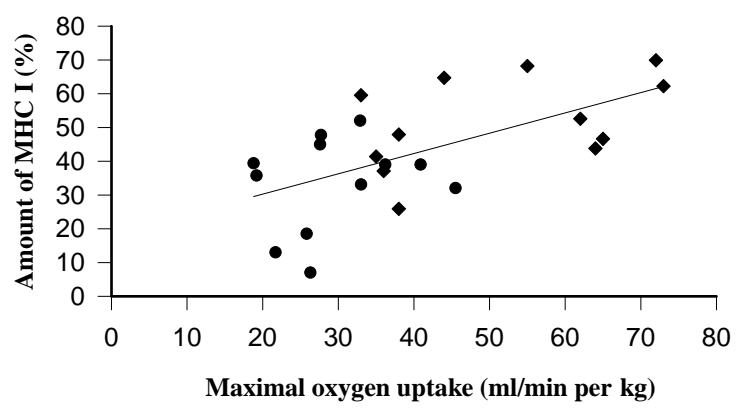

B

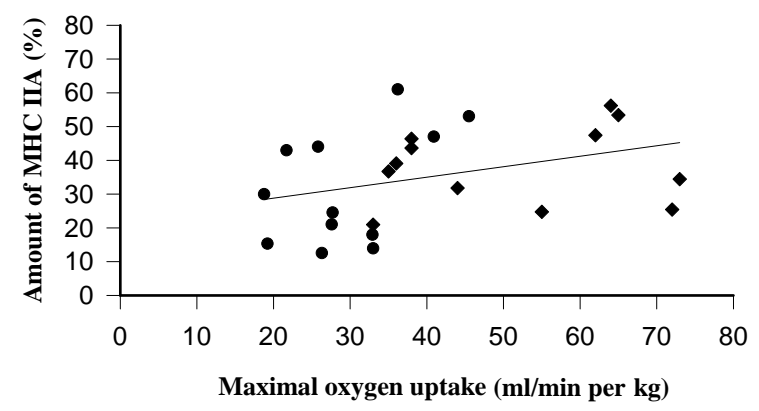

C

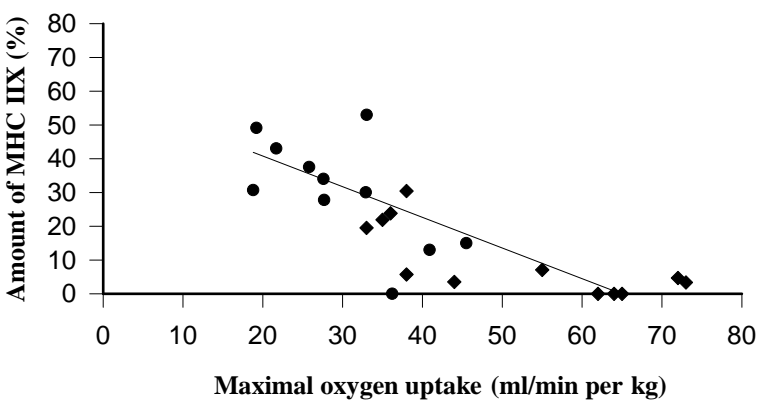

Figure 3 Correlation between $\mathrm{VO}_{2}$ max per $\mathrm{kg} \mathrm{BW}(\mathrm{ml} / \mathrm{min}$ per $\mathrm{kg}$ ) and the electrophoretically determined amount of $\mathrm{MHC} \mathrm{I}$, $r=0.60, P<0.05(\mathrm{~A}) ; \mathrm{MHC} \| \mathrm{A}, r=0.35, P<0.09(\mathrm{~B}) ;$ and $\mathrm{MHC}$ IIX, $r=-0.72, P<0.001(\mathrm{C})$ in GHD patients $(\bullet)(n=12)$ (beforetreatment values were used) and age-matched control subjects ( $\bullet$ $(n=12) . r$ and $P$ values were obtained using linear regression.

We searched for a relationship between the severity of GHD (measured as IGF-I concentration) and the MHC composition. Both for the entire group of GHD patients and for the individual groups, no significant correlations

Table 4 Electrophoretically determined amount of MHC isoforms in GHD patients before and after treatment with either placebo (GHD-PLA) or rhGH (GHD-GH) for 6 months. Values are mean \pm S.E.M.

\begin{tabular}{lccccc}
\hline & \multicolumn{2}{c}{ GHD-PLA } & & \multicolumn{2}{c}{ GHD-GH } \\
\cline { 2 - 3 } \cline { 5 - 6 } & $\begin{array}{c}\text { Before } \\
(n=11)\end{array}$ & $\begin{array}{c}\text { After } \\
(n=11)\end{array}$ & & $\begin{array}{c}\text { Before } \\
(n=11)\end{array}$ & $\begin{array}{c}\text { After } \\
(n=11)\end{array}$ \\
\hline MHC I (\%) & $32.9 \pm 2.9$ & $34.0 \pm 4.0$ & & $39.5 \pm 4.0$ & $34.5 \pm 3.0$ \\
MHC IIA (\%) & $34.1 \pm 5.1$ & $27.1 \pm 5.5$ & & $35.5 \pm 5.3$ & $33.8 \pm 5.0$ \\
MHC IIX (\%) & $32.9 \pm 5.3$ & $39.0 \pm 6.4$ & & $24.9 \pm 7.0$ & $31.7 \pm 5.9$ \\
\hline
\end{tabular}


were found between the IGF-I concentration and the amount of MHC I, MHC IIA and MHC IIX (data not shown). Furthermore, we searched for a relationship between the body composition, measured as BW, LBM, fat mass and BMI, and the MHC composition. Both for the entire group of GHD patients and controls and for the individual groups, no significant correlations were found between any measure of body composition and the amount of MHC I, MHC IIA and MHC IIX (data not shown).

\section{Discussion}

We investigated the effect of 6 months of treatment with rhGH on vastus lateralis muscle MHC composition in GHD patients. Furthermore, the muscle MHC composition in the GHD patients was compared with a group of age-matched controls. The amount of MHC IIX was higher and the amount of MHC I was lower in the GHD patients than in controls and treatment with rhGH for 6 months did not change fibre type distribution in GHD. Thus we, for the first time, precisely determined the consequence of acquired GHD and the effect of $\mathrm{GH}$ treatment on MHC composition in GHD.

In the present study, we classified the skeletal muscle fibres as MHC I, MHC IIA and MHC IIX using SDS-PAGE and found large differences in the muscle MHC composition between GHD patients and controls. Our results are in contrast to the previously published studies using traditional histochemistry for determining fibre type composition (20-22), and also in contrast to the recent study by Bottinelli et al. who reported an identical MHC isoform distribution in a small group $(n=5)$ of GHD patients which was compared with a group of agematched controls (although a tendency to a larger proportion of MHC X in the five GHD patients is reported) (23). The discrepancy between the study by Bottinelli et al. and the present study is not clear, but it cannot be excluded that childhood onset GHD, which was studied by Bottinelli et al. could be of importance for the MHC composition, since it was recently demonstrated that significant clinical and biochemical differences exist between childhood and adulthood onset of GHD, reporting among other features, differences in height, body composition, IGF-I and insulin-like growth factor binding protein-3 (24). However in the present study, excluding the two patients with childhood onset GHD did not significantly influence the results. Furthermore, in contrast to previous studies using histochemistry, we determined the amount of the different MHC isoforms in the muscle using SDS-PAGE, since using this method, variations in fibre size and the presence of hybrid fibres are taken into account (25).

Since the MHC isoform composition in a muscle to a large extent determines the contractile properties in that muscle (1), this means that the muscle function in the GHD patients can be expected to be different from the normal population. Several $(8,26,27)$, but not all groups (23) have reported an altered muscle performance in GHD patients. Our results showing an increased proportion of MHC IIX would indicate a faster muscle in GHD compared with the control group. This is supported by Rutherford et al. who recently found in a group of GHD patients a significantly faster quadriceps muscle with a possible greater fatigability compared with a group of age-matched controls (8). Other possible consequences of a high proportion of MHC IIX includes decreased insulin sensitivity (28), increased glycolytic and decreased oxidative capacity and a decreased capillarization (29).

The mechanism behind the altered MHC composition in GHD patients is not known but from our data it is possible to give plausible explanations. In addition to heredity (30) there are a variety of factors important for the muscle composition, including neural input, functional usage pattern, ageing and hormone levels (reviewed in ref. 31). In rats, we and others have shown that both $\mathrm{GH}$ and thyroid hormones are important in determining the MHC composition in skeletal muscles $(9,32)$. As the patients were euthyroid before and during the treatment, an influence from thyroid hormone seems unlikely. If $\mathrm{GH}$ is important in determining the MHC composition, it could be speculated that there was a time-dependent relationship between the duration of GHD and the proportion of MHC IIX in the skeletal muscles. This hypothesis seems unlikely since no correlation was found between the amount of MHC IIX and the estimated number of years the patients had been deficient in GH $(r=0.06$, $P=0.78)$. Furthermore, no correlation was found between the amount of MHC IIX and the IGF-I concentration before treatment, meaning the severity of GHD is not important for the MHC composition. A more likely explanation for the increased amount of MHC IIX is the low physical fitness in the GHD patients. In the present study the physical fitness was expressed as $\mathrm{VO}_{2} \max , \mathrm{VO}_{2}$ max per $\mathrm{kg} \mathrm{BW}$ and $\mathrm{VO}_{2}$ max per $\mathrm{kg}$ LBM, and was in all instances found to be significantly lower in the GHD patients compared with the controls (Table 3). Since the physical fitness could be important in determining the MHC composition, we hypothesize that the high amount of MHC IIX is a result of a low activity level. This is supported by the relatively strong correlations found between the MHC isoform composition and the $\mathrm{VO}_{2}$ max per kg BW (Fig. 3). However, since the $r$ values never exceed 0.72 it is equally important to note that only around $50 \%$ of the variation in MHC composition can be explained by the $\mathrm{VO}_{2}$ max per $\mathrm{kg}$ $\mathrm{BW}$. Doing similar calculations using the $\mathrm{VO}_{2}$ max or the $\mathrm{VO}_{2}$ max per kg LBM did not further increase the $r$ values. Furthermore, including the body composition (BMI, LBM or fat mass) in the equation did not significantly increase the $r$ values, suggesting less importance of these variables compared with the physical fitness. Thus, the ability to take up oxygen, independently of BW, LBM and fat mass, seems to be of primary importance for the 
MHC composition. These findings are in accordance with Utriainen et al. who, in a group of young healthy men, found a positive relationship between the number of type I fibres and the $\mathrm{VO}_{2}$ max per $\mathrm{kg} \mathrm{BW}$ and a negative relationship between the number of type IIB (IIX in the present study) fibres and the $\mathrm{VO}_{2}$ max per $\mathrm{kg} \mathrm{BW}$ (28). Furthermore, a positive relationship has been shown both between the area occupied by and the number of type I fibres on one hand and the $\mathrm{VO}_{2}$ max per $\mathrm{kg} \mathrm{BW}$ on the other hand $(33,34)$. In contrast, Wade et al. showed that the proportion of type I fibres in a group of normal men is closely related to the percentage of body fat but not to $\mathrm{VO}_{2}$ max per $\mathrm{kg}$ LBM (35). The reason for this discrepancy is not clear.

Thus, the importance of $\mathrm{GH}$ in muscle fibre differentiation seems questionable, since 6 months of treatment with rhGH had no effect on the MHC composition. Previously published work studying the effect of $\mathrm{GH}$ treatment in GHD patients has used traditional histochemistry for determining fibre type composition $(20,21)$ and the fibre types have only been classified as type I fibres and type II fibres. Since in human skeletal muscle large differences in both contractile and metabolic properties exist within the type II fibres (29), the myosin composition of these fibres was determined in the various subgroups in the present study. Our results support the conclusions drawn by the earlier studies that there is no change in the number of type I and type II fibres (amount of MHC I and MHC II) following 6 months of $\mathrm{GH}$ treatment in human skeletal muscle $(20,21)$. We can now further conclude that no change in the amount of MHC IIA and MHC IIX takes place during treatment of GHD patients with rhGH. So, although several direct effects on skeletal muscle undoubtedly can be evoked by $\mathrm{GH}$ treatment $(7,27)$ we and others have found no effect of treatment with GH on fibre type or MHC composition in GHD patients $(20,21)$, and in normal humans $(36,37)$, leaving a primary role for $\mathrm{GH}$ in muscle fibre differentiation unlikely.

Our GHD patients were treated for 6 months but it is possible that extending the treatment period could have showed an effect of GH on MHC composition. However, since the GHD patients responded well to the rhGH treatment (as judged by the increase in IGF-I) and since significant changes in human skeletal MHC composition have been shown to occur both following exercise training for 12 and 19 weeks $(38,39)$ and following electrical stimulation for 6 months (40), we do not think that treating the GHD patients for a longer time would have changed the conclusion of the present study.

Finally, one could speculate why the GHD patients are unfit. Since the $\mathrm{VO}_{2}$ max to a large extent is determined by the pump capacity of the heart (41) and since a low maximal heart rate (6), and a low cardiac output (42) have been reported in GHD patients this could be part of the explanation for the reduced physical fitness. We did not measure maximal heart rate in the group of controls but if we estimate it from the mean age of the subjects a value around 180 beats/min is obtained. Since this value is higher than the maximal heart rate obtained in the group of GHD patients, it is possible that a reduction in pump capacity could be responsible for the reduced fitness.

In conclusion, MHC isoform composition in GHD patients is changed compared with age-matched controls. In these patients the amount of MHC IIX is higher and the amount of MHC I is lower than in controls. Treatment with rhGH for 6 months does not change the MHC isoform composition in GHD patients, leaving a primary role of GH in muscle fibre differentiation unlikely. The mechanism behind the differences in MHC content can to a large extent be explained by differences in physical fitness.

\section{Acknowledgements}

The present study was supported by grants from The National Danish Research Foundation (grant 504-14), Pharmacia \& Upjohn, Novo Nordisk Insulin Foundation and Albert Påhlssons Foundation. We are grateful to Esa Laurila, Gertrud Ahlqvist and Marianne Lundberg for skilful technical assistance.

\section{References}

1 Larsson L \& Moss RL. Maximum velocity of shortening in relation to myosin isoform composition in single fibres from human skeletal muscles. Journal of Physiology 1993 472 595-614.

2 DeNardi C, Ausoni S, Moretti P, Gorza L, Velleca M, Buckingham $\mathrm{M}$ et al. Type 2X-myosin heavy chain is coded by a muscle fiber type-specific and developmentally regulated gene. Journal of Cell Biology 1993123 823-835.

3 Ennion S, Sant'Ana Pereira JAA, Sargeant AJ, Young A \& Goldspink G. Characterization of human skeletal muscle fibres according to the myosin heavy chains they express. Journal of Muscle Research and Cell Motility 199516 35-43.

4 Tanner JM. Effect of human growth hormone treatment for 1 to 7 years on growth of 100 children, with growth hormone deficiency, low birth weight, inherited smallness, Turner's syndrome, and other complaints. Archives of Disease in Childhood $197146745-782$.

5 Tanner JM, Hughes PC \& Whitehouse RH. Comparative rapidity of response of height, limb muscle and limb fat to treatment with human growth hormone in patients with and without growth hormone deficiency. Acta Endocrinologica 197784 681-696.

6 Jørgensen JOL, Pedersen SA, Thuesen L, Jørgensen J, IngemannHansen T, Skakkebæk NE et al. Beneficial effects of growth hormone treatment in GH-deficient adults. Lancet 1989 i $1221-$ 1225.

7 Cuneo RC, Salmon F, Wiles CM, Hesp R \& Sönksen PH. Growth hormone treatment in growth hormone-deficient adults. II. Effects on exercise performance. Journal of Applied Physiology $199170695-700$.

8 Rutherford OM, Beshyah SA, Schott J, Watkins Y \& Johnston DG. Contractile properties of the quadriceps muscle in growth hormone deficient hypopituitary adults. Clinical Science $1995 \mathbf{8 8}$ 67-71.

9 Daugaard JR, Laustsen JL, Hansen BS \& Richter EA. Growth hormone induces muscle fibre type transformation in growth hormone deficient rats. Acta Physiologica Scandinavica 1998164 119-126. 
10 Ayling CM, Moreland BH, Zanelli JM \& Schulster D. Human growth hormone treatment of hypophysectomized rats increases the proportion of type-1 fibres in skeletal muscle. Journal of Endocrinology 1985123 429-435.

11 Loughna PT \& Bates PC. Interactions between growth hormone and nutrition in hypophysectomised rats: skeletal muscle myosin heavy chain mRNA levels. Biochemical and Biophysical Research Communications 1994198 97-102.

12 Roy RR, Tri C, Grossman EJ, Talmadge RJ, Grindeland RE, Mukku VR et al. IGF-I, growth hormone, and/or exercise effects on non-weight-bearing soleus of hypophysectomized rats. Journa of Applied Physiology 199681 302-311.

13 Grossman EJ, Grindeland RE, Roy RR, Talmadge RJ, Evans J \& Edgerton VR. Growth hormone, IGF-I, and exercise effects on non-weight-bearing fast muscles of hypophysectomized rats. Journal of Applied Physiology 199783 1522-1530.

14 Jørgensen JOL, Vahl N, Hansen TB, Thuesen L, Hagen C \& Christiansen JS. Growth hormone versus placebo treatment for one year in growth hormone deficient adults: increase in exercise capacity and normalization of body composition. Clinical Endocrinology $199645681-688$.

15 Jørgensen JOL, Thuesen L, Møller J, Ovesen P, Skakkebæk NE \& Christiansen JS. Three years of growth hormone treatment in growth hormone-deficient adults: near normalization of body composition and physical performance. European Journal of Endocrinology $1994130224-228$

16 Åstrand I. Aerobic work capacity in men and woman with special reference to age. Acta Physiologica Scandinavica 1960169 49-92.

17 Åstrand P-O \& Rodahl K. In Textbook of Work Physiology, edn 3, ch 7, pp 295-353. New York: McGraw-Hill, 1970.

18 Bergström J. Muscle electrolytes in man. Scandinavian Journal of Clinical and Laboratory Investigation 196268 1-110.

19 Betto DD, Zerbato E \& Betto R. Type 1, 2A, and 2B myosin heavy chain electrophoretic analysis of rat muscle fibers. Biochemical and Biophysical Research Communications 1986138 981-987.

20 Whitehead HM, Gilliland JS, Allan IV \& Hadden DR. Growth hormone treatment in adults with growth hormone deficiency: effect on muscle size and proportions. Acta Paediatrica Scandinavica $198935665-67$.

21 Cuneo RC, Salomon F, Wiles CM, Round JM, Jones D, Hesp R \& Sönksen PH. Histology of skeletal muscle in adults with $\mathrm{GH}$ deficiency: comparison with normal muscle and responses to $\mathrm{GH}$ treatment. Hormone Research 199237 23-28.

22 Salomon F, Cuneo RC, Umpleby AM \& Sönksen PH. Interactions of body fat and muscle mass with substrate concentrations and fasting insulin levels in adults with growth hormone deficiency. Clinical Science 199487 201-206.

23 Bottinelli R, Narici M, Pellegrino MA, Kayser B, Canepari M, Faglia $\mathrm{G}$ et al. Contractile properties and fiber type distribution of quadriceps muscles in adults with childhood-onset growth hormone deficiency. Journal of Clinical Endocrinology and Metabolism 199782 4133-4138.

24 Attanasio AF, Lamberts SW, Matranga AM, Birkett MA, Bates PC, Valk NK et al. Adult growth hormone (GH)-deficient patients demonstrate heterogeneity between childhood onset and adult onset before and during human GH treatment. Journal of Clinical Endocrinology and Metabolism 199782 82-88.

25 Harridge SD, Bottinelli R, Canepari M, Pellegrino MA, Reggiani C, Esbjörnsson $\mathrm{M}$ et al. Whole-muscle and single-fibre contractile properties and myosin heavy chain isoforms in humans. Pflügers Archiv 1996432 913-920.

26 Cuneo RC, Salomon F, Mark Wiles C \& Sönksen PH. Skeletal muscle performance in adults with growth hormone deficiency. Hormone Research 199033 55-60.
27 Brat O, Ziv I, Klinger B, Avraham M \& Laron Z. Muscle force and endurance in untreated and human growth hormone treated or Insulin-Like Growth Factor-1-treated patients with growth hormone deficiency or Laron syndrome. Hormone Research 1997 $4745-48$.

28 Utriainen T, Holmäng A, Björntorp P, Mäkimattila S, Sovijärvi A, Lindholm $\mathrm{H}$ et al. Physical fitness, muscle morphology, and insulin-stimulated limb blood flow in normal subjects. American Journal of Physiology 1996270 E905-E911.

29 Saltin B \& Gollnick PD. Skeletal muscle adaptability: significance for metabolism and performance. In Handbook of Physiology, sec 10, ch 19, pp 555-631. Eds LD Peachey, RH Adrian \& SR Geiger. Bethesda, MD: American Physiological Society, 1983.

30 Komi PV, Viitasalo JHT, Havu M, Thorstensson A, Sjödin B \& Karlsson J. Skeletal muscle fibres and muscle enzyme activities in monozygous and dizygous twins of both sexes. Acta Physiologica Scandinavica $1977100385-392$.

31 Staron RS \& Johnson P. Myosin polymorphism and differential expression in adult human skeletal muscle. Comparative Biochemical Physiology 1993106 463-475.

32 Caiozzo VJ. Herrick RE \& Baldwin KM. Influence of hyperthyroidism on maximal shortening velocity and myosin isoform distribution in skeletal muscles. American Journal of Physiology 1991 261 C285-C295.

33 Gregor RJ, Edgerton VR, Rozenek R \& Castleman KR. Skeletal muscle properties and performance in elite female track athletes. European Journal of Applied Physiology 198147 355-364.

34 Bergh U, Thorstensson A, Sjödin B, Hulten B, Piehl K \& Karlsson J. Maximal oxygen uptake and muscle fiber types in trained and untrained humans. Medicine and Science in Sports $197810151-$ 154.

35 Wade AJ, Marbut MM \& Round JM. Muscle fibre type and aetiology of obesity. Lancet 1990335 805-808.

36 Taaffe DR, Pruitt L, Reim J, Hintz RL, Butterfield G, Hoffman AR \& Marcus R. Effect of recombinant human growth hormone on the muscle strength response to resistance exercise in elderly men. Journal of Clinical Endocrinology and Metabolism $1994791361-$ 1366.

37 Yarasheski KE, Campbell JA, Smith K, Rennie MJ, Holloszy JO \& Bier DM. Effect of growth hormone and resistance exercise on muscle growth in young men. American Journal of Physiology 1992262 E261-E267.

38 Andersen JL, Klitgaard H \& Saltin B. Myosin heavy chain isoforms in single fibres from $\mathrm{m}$. vastus lateralis of sprinters: influence of training. Acta Physiologica Scandinavica 1994151 135-142.

39 Adams GR, Hather BM, Baldwin KM \& Dudley GA. Skeletal muscle myosin heavy chain composition and resistance training. Journal of Applied Physiology 1993 74 911-915.

40 Andersen JL, Mohr T, Biering-Sørensen F, Galbo H \& Kjær M. Myosin heavy chain isoform transformation in single fibres from $\mathrm{m}$. vastus lateralis in spinal cord injured individuals: effects of long-term functional electrical stimulation (FES). Pflügers Archiv $1996431513-518$.

41 Andersen P \& Saltin B. Maximal perfusion of skeletal muscle in man. Journal of Physiology 1985366 233-249.

42 Shahi M, Beshyah SA, Hackett D, Sharp PS, Johnston DG \& Foale RA. Myocardial dysfunction in treated adult hypopituitarism: a possible explanation for increased cardiovascular mortality. British Heart Journal $19926792-96$.

Received 10 March 1999

Accepted 9 July 1999 